\title{
Advocacia em saúde no Brasil contemporâneo
}

\section{Health advocacy in contemporary Brazil}

\section{Sueli Gandolfi Dallari, Rosemary Barber-Madden, Marília de Castro Torres-Fernandes, Nur Shuqaira Mahmud Said Abdel Qader Shuqair e Helena Akemi Watanabe}

Departamento de Prática de Saúde Pública da Faculdade de Saúde Pública da Universidade de São Paulo. São Paulo, SP - Brasil (S.G.D., H.A.W.); "Public Health of Faculty of Medicine of Columbia University" (R.B.M.); Centro de Estudos e Pesquisa de Direito Sanitário da Universidade de São Paulo. São Paulo, SP - Brasil (M.C.T.F.); Núcleo de Pesquisa de Direito Sanitário da Universidade de São Paulo. São Paulo, SP - Brasil (N.S.M.S.A.Q.S.)

\begin{abstract}
Resumo
Apresenta-se o conceito de advocacia em saúde, por meio da descrição de seus elementos, sua prática e seus agentes. A necessidade da formulação de tal conceito surge da função que tem a universidade, entre outras, de identificar demandas sociais e oferecer alternativas que busquem a superação de obstáculos. A ênfase é centrada na participação social, assegurada na Constituição, promulgada em 1988, e que desde então tem sido tomada como referência no desenvolvimento dos mecanismos de construção da cidadania, especialmente quando relacionada à conquista do direito à saúde.
\end{abstract}

Direito à saúde, legislação \& jurisprudência. Defesa do paciente, legislação \& jurisprudência. Participação comunitária.

\begin{abstract}
The concept of health advocacy is presented by means of a description of its elements, practice and agents. The need to formulate this concept derives from one of the main functions of the university: the identification of social demands and the presentation of alternatives that aim at eliminating obstacles to their fulfilment. Social participation, as guaranteed by the 1988 Constitution, understood as an opportunity for the development of mechanisms for the construction of citizenship, especially as related to the conquist of the right to health, is emphasized.
\end{abstract}

Health rights, legislation. Patient advocacy, legislation. Consumer participation. 


\section{O PAPEL DA UNIVERSIDADE NA ADVOCACIA EM SAÚDE}

Interessado na investigação de novas formas de atuação nas políticas de saúde pública, o Centro de Estudos e Pesquisas de Direito Sanitário (CEPEDISA) e o Núcleo de Pesquisa em Direito Sanitário (NAP-DISA) vêm desenvolvendo pesquisas na área de advocacia em saúde pública. As investigações objetivaram identificar demandas da sociedade, estudando as formas de reivindicações utilizadas por grupos comunitários de algumas regiões da cidade de São Paulo e prestando atendimento à comunidade, e têm servido de base para o ensino da advocacia em saúde nos cursos de pós-graduação da Faculdade de Saúde Pública da Universidade de São Paulo Brasil, tanto naqueles chamados lato sensu como nos stricto sensu. Acredita-se que a pesquisa, o ensino e a prestação de serviços em advocacia em saúde possam superar a contradição ética inerente à Universidade contemporânea.

De fato, a Universidade atual vive, evidentemente, um conflito. Criada como o lugar onde se cultivaria o saber entre os sábios, transformou-se em instrumento de libertação que tornava possível a democracia liberal burguesa e hoje deve gerar valores sociais economicamente mensuráveis. Procura-se escamotear a contradição atual, afirmando-se que a Universidade tem as funções de pesquisar, ensinar e prestar serviços à comunidade. O conflito se evidencia, contudo, quando se exige a mensuração econômica dos valores criados. Isto por que o fator econômico passa a influir, direta ou indiretamente, sobre o que se pesquisa, o que se ensina e que tipo de serviço a Universidade presta*.

Assim, a Universidade pode estabelecer linhas de pesquisa em advocacia em saúde que levem à compreensão dos modos de efetivação do direito à saúde e mesmo ao desenvolvimento de técnicas que permitam a avaliação do impacto das estratégias utilizadas, provocando, então, a discussão dos sábios com os sábios. Também, enquanto instituição de ensino destinada a formar o cidadão que viabiliza a democracia, a Universidade estará exercendo sem ambigüidade seu papel ao se dedicar ao ensino da advocacia em saúde, seja em cursos regulares de graduação ou pós-graduação, seja em cursos de extensão cultural para pessoas das mais diversas categorias educacionais, empregando modernas técnicas pedagógicas. $\mathrm{E}$ a prestação de serviços em advocacia em saúde cum- pre, sem dúvida, a obrigação da Universidade gerar valores sociais. Valores estes que têm sobretudo conteúdo moral, mas que comportam mensuração econômica, inclusive.

Da experiência nasceu a necessidade de se afastar a idéia de advocacia em saúde daquela da advocacia dos bacharéis, criando-se um conceito de advocacia em saúde e adequando-o à realidade brasileira. Este se concretizou como processo que utiliza conjunto de estratégias políticas visando a promover direitos não respeitados, através de meios legais e éticos, a favor de grupos sociais desfavorecidos ou oprimidos. Assim, a advocacia em saúde desenvolve ações que procuram influenciar autoridades e particulares, sensibilizando-os para carências e necessidades sanitárias diversas.

\section{CONSTRUINDO A PARTICIPAÇÃO SOCIAL}

Baseados nas concepções filosóficas do século XVIII, os ideais democráticos da supremacia da vontade do povo, respeitando a liberdade e a igualdade, têm enfrentado dificuldades na sua garantia no decorrer do tempo, até a atualidade. A participação do povo nas sociedades democráticas contemporâneas é fato recente. O sufrágio universal e a igualdade do voto, salvo o caso dos Estados Unidos, são conquistas dos primeiros decênios deste século. A instituição de partidos políticos como viabilização das formas direta e semidireta das democracias representativas também é historicamente recente, sendo que muitos países em desenvolvimento tiveram este processo interrompido por regimes não democráticos, impossibilitando a mobilização e o controle social por parte de seus cidadãos ${ }^{4}$.

O corpo legislativo demonstrou-se, com o tempo, insuficiente como ideal de representação dos cidadãos. Com a interpenetração do Estado na sociedade, a presença do Estado na economia e a expansão da cidadania política ocorreu uma fragmentação dos interesses sociais e as instituições tradicionais foram combinando formas corporativas como mecanismo de representação. Então, surgiram as associações e sindicatos de classes profissionais que reivindicavam por seus membros, o que também se mostrou insuficiente**.

Ora, o liberalismo do século dezoito moldou instituições jurídicas destinadas a um indivíduo abstrato, apenas conceitualmente igual aos demais indiví-

\footnotetext{
* Sobre o tema veja Bird e col. ${ }^{3}(1993)$.

** Sobre democracia contemporâneas e representação política ver Bobbio ${ }^{5}$ (1992); Campilongo ${ }^{7}$ (1991); e Dallari ${ }^{11}$ (1991).
} 
duos, uma vez que não se cogitava das diferenças derivadas de sua inserção social. E no século vinte persistem as instituições jurídicas desenvolvidas há duzentos anos. Assim, para que se possa compreender o processo de constitucionalização da proteção aos interesses difusos - o mais avançado estágio do reconhecimento institucional - é indispensável começar por conhecer o conceito de interesses difusos. Mancuso $^{17}$, após exaustivo exame dos termos interesse social, interesse geral e interesse público, concluiu que eles são praticamente equivalentes e que distingui-los não traria contribuição relevante para o estudo dos interesses metaindividuais.

Entretanto, dada sua força ideológica, é necessário separar o interesse coletivo do interesse individual, ou o público do privado. Tal contraste - evidente para o direito romano - foi buscado artificialmente na construção do Estado liberal burguês, no século dezoito. Com efeito, a promulgação da Lei "Le Chapelier" (França, 1791), extinguindo as corporações e pretendendo impedir a formação de grupos de mais de vinte pessoas, testemunha tal procura. Reconhecia-se apenas o interesse particular de cada indivíduo e o interesse geral do Estado. Todavia, como já assinalaram eminentes juristas, quando o direito ignora a realidade, esta se vinga ignorando o direito. E já em 1884, na França, era reconhecida a liberdade sindical. Definia-se, assim, um interesse coletivo posto entre o interesse público e o privado. Hoje, a proliferação de grupos reivindicando interesses coletivos diversos, muitas vezes conflitantes entre si e com o Estado, permite distinguir, quanto à amplitude abrangida, os interesses predominantemente individuais, ou privados, daqueles predominantemente coletivos, ou de grupos, e dos públicos, ou do Estado. Isto por que, também nessa ponta, o Estado começa a conviver com a concorrência dos grupos sociais, assimilando - sob certos limites e condições - a participação de tais associações na gestão dos serviços públicos.

Portanto, os interesses difusos, que contam com pouco mais de uma década de elaboração jurídica específica, não são interesses nem coletivos nem públicos, mas - segundo a abrangência - são mais amplos que o interesse público, pois se referem ao homem e não ao cidadão. Do mesmo modo, os interesses difusos se situam entre o interesse legítimo e o simples*.

Parece óbvio que sempre tenham existido interesses difusos, entretanto, sem qualquer dúvida, a socie- dade contemporânea os exaltou, provocando o estudo sistemático do tema. Os sistemas jurídicos modernos foram construídos tendo por base a tutela dos direitos dos indivíduos. O Estado liberal burguês, portanto, se equipou para proteger o direito subjetivo. A organização do proletariado, conseqüente à Revolução Industrial, revelou, contudo, que existem direitos que são comuns a toda uma categoria de pessoas e que os conflitos também podem se estabelecer entre grandes grupos de indivíduos. Os sistemas jurídicos responderam a tais mudanças, com o costumeiro retardo, quando formalizaram - no século seguinte - os contratos de adesão e os contratos coletivos de trabalho, por exemplo.

A globalização da vida social evidenciou, nos últimos anos do século vinte, a necessidade de proteger interesses que não são exclusivos do indivíduo ou mesmo de grupos sociais. Definem-se interesses de toda a humanidade, não apenas das gerações presentes, mas, igualmente, das futuras. E a sociedade espera que o direito desenvolva os instrumentos capazes de viabilizar a tutela desses interesses.

Entretanto, considerando especialmente as características mais freqüentemente apontadas pela doutrina**, os interesses difusos têm enfrentado diversas dificuldades para serem assumidos pelo direito. Com efeito, a indeterminação ou a difícil determinação dos seus titulares agride a base tradicional do sistema jurídico liberal burguês, que tem o indivíduo como titular dos direitos subjetivos. Também a indivisibilidade em quotas atribuíveis a determinada pessoa ou grupos de pessoas afronta o direito tradicional, pois a satisfação de um interesse difuso para deterninado indivíduo representa a satisfação para toda a classe. Igualmente, para o sistema jurídico liberal burguês existem limites à conflituosidade colocados nas próprias normas jurídicas, limites esses que não existem quando se trata de interesses difusos, onde constantemente estão envolvidas opções políticas que contrapõem um grupo de pessoas a outro. E, do mesmo modo, os interesses difusos têm sua origem nos fatos - e são por isso mutáveis no tempo e no espaço -, diferentemente dos direitos, assentados no plano ético-normativo. Outra série de obstáculos postos à assumpção dos interesses difusos pelos sistemas jurídicos advém de razões políticas, basicamente da ameaça que pode representar para o sistema político liberal a pulverização da autoridade estatal $* * *$.

\footnotetext{
* O direito desconhece o interesse simples e protege amplamente o direito subjetivo - as prerrogativas individuais especialmente tuteladas pelo Estado - destinado ao interesse legítimo uma proteção limitada, uma vez que não podem ser ignorados ou preteridos.

** Apenas como exemplo, ver Barbosa $\operatorname{Moreira}^{2}(1981)$; Grinover $^{12}$ (1984); e Villone ${ }^{20}(1978)$

*** Discussão exaustiva do tema em Mancuso $^{17}$ (1988) p. 88-101.
} 
No Brasil, a discussão teórica sobre a proteção jurídica dos interesses difusos foi timidamente introduzida com a Lei 6.938/81, que dispunha sobre a Política Nacional do Meio Ambiente, e implementada com a Lei 7.347/85, que disciplinou a ação civil pública em matéria ambiental e do consumidor. Todavia, algumas leis bastante anteriores tinham já tratado do tema: Lei 1.390/51, sobre o preconceito de raça e de cor; Lei 2.889/56, sobre o genocídio; Lei Delegada 4/62, sobre o controle do abastecimento, por exemplo. De fato, foi a ebulição teórica da primeira metade da década de 1980 que influenciou decisivamente o direito brasileiro, provocando o reconhecimento dos interesses coletivos na futura Constituição federal.

\section{A PARTICIPAÇÃO SOCIAL NA SAÚDE}

Os brasileiros vivem simultaneamente duas experiências difíceis: aprender a democracia e aprender as formas de democracia contemporâneas. Os setores sociais interessados na saúde buscavam, já no período pré-constituinte (especialmente a partir de 1985), a afirmação da saúde como um direito e o reconhecimento da necessária ampliação das formas de participação popular ${ }^{6}$. E a Carta de 1988, declarando a constituição do Estado Democrático de Direito*, reforçou a busca do ideal democrático por cidadãos atentos à coisa pública, que podem se manter informados e participar das políticas públicas. Deixando clara, também, a necessidade de participação da comunidade nas ações e serviços públicos de saúde (C.F. art.198, III).

Assim, o termo "advogar", tradicionalmente usado apenas para designar a atividade profissional do bacharel em direito regularmente licenciado, passa, também, a conformar uma nova expressão: a "advocacia em saúde", significando a reivindicação pelo direito à saúde.

O termo advocacia, assim utilizado, tem sua origem no inglês "advocacy"13,14. Nascido das experiências da democracia americana, que historicamente desenvolveram comportamentos de reivindicações de direito de modo característico e próprio, tem o significado de ações individuais e de grupos organizados que procuram influir sobre as autoridades e os particulares para que fiquem mais sensíveis às carências e necessidades diversas que emergem na sociedade.

É necessário esclarecer, contudo, que a defesa e o cuidado da saúde pública no Brasil são interesses da sociedade já abrigados pelo sistema jurídico, não comportando conflitos interindividuais, e sim entre o Estado e os indivíduos. A saúde pública não pressupõe mais, portanto, aquela conflituosidade máxima acima referida por que não podem ser juridicamente sustentados interesses contrários a ela, sob o argumento de que a saúde não é declaradamente um direito. Assim, portanto, a saúde pública não se caracteriza como interesse difuso, mas como uma liberdade pública ou direito subjetivo público. Entretanto, como o direito à saúde, tal qual definido na Constituição, depende de políticas sociais e econômicas (art.196), será sempre indispensável que se considere a defesa dos interesses difusos quando se advoga em saúde.

\section{ELEMENTOS DA ADVOCACIA EM SAÚDE}

A advocacia em saúde baseia-se no princípio de que as pessoas têm direitos básicos positivados juridicamente, ou não positivados, que são desrespeitados ou não garantidos.

No Brasil, a Constituição Federal de 1988 inclui a saúde no capítulo da seguridade social, que tem como objetivos, entre outros, a universalidade de cobertura e atendimento e o caráter democrático e descentralizado da gestão administrativa, com a participação da comunidade. A saúde é definida como um direito de todos e um dever do Estado, e as ações e serviços de saúde, como sendo de relevância pública, "cabendo ao Poder Público dispor, nos termos da lei, sobre sua regulamentação, fiscalização e controle, devendo sua execução ser feita diretamente ou através de terceiros..." (arts. 196 e 197) ${ }^{10}$. Inclui também os chamados remédios constitucionais - artigos da Constituição que prevêem as formas de defesa de que o cidadão ou a comunidade podem lançar mão nos casos em que os direitos declarados constitucionalmente são violados.

Assim, apesar dos particulares também serem alvo da advocacia em saúde, como, por exemplo, na reivindicação pela destinação de leitos de hospitais privados segundo a necessidade definida pelo perfil de morbi-mortalidade de uma comunidade, e não pela lucratividade das especialidades, o responsável pela garantia do direito à saúde, em última instância, é o Estado.

Entretanto, não basta que o direito à saúde $\mathrm{e}$ suas garantias estejam expressos em documentos, é necessário torná-lo um direito garantido de fato. 
Na nossa sociedade, os direitos sociais não são obtidos por concessão espontânea, mas conquistados pelas classes menos favorecidas. Como diz Teixeira ${ }^{19}$, a conquista dos direitos sociais deveuse às "lutas travadas pela classe trabalhadora em torno da ampliação da noção de igualdade: de uma igualdade formal a uma igualdade na apropriação da riqueza social".

Atualmente, no Brasil, o chamado setor saúde, dentre as áreas sociais, é um dos mais politizados e conta com maior presença de grupos da comunidade participando e pressionando por seus interesses ${ }^{9}$.

Considerando que o direito à saúde não alcança a totalidade da população, e que, apesar de ser necessário reivindicar a sua efetivação, nem todos os grupos direcionam seus esforços de modo eficaz, a advocacia em saúde surge da necessidade de fortalecer a população hipossuficiente por omissões institucionais no processo de reivindicação do direito à saúde.

Segundo Barber-Madden ${ }^{1}$, a advocacia em saúde envolve esforços individuais e de grupos organizados que tratam de influir sobre as autoridades para que sejam mais sensíveis às necessidades dos eleitores, dos consumidores e daqueles que intervêm no processo político, assim como dos grupos pobres e desprivilegiados.

As ações básicas da advocacia são relacionadas à "alteração das leis, ao monitoramento do legislativo, à elaboração e implementação do orçamento, aos processos administrativos e, às vezes, a profissionais ou conjunto de profissionais, não com a mudança de indivíduos" $" 14$.

A advocacia em saúde, segundo Knitzer $^{14}$, baseiase nos seguintes pressupostos:

- as pessoas têm ou devem ter certos direitos básicos que são reforçados por normas legais e procedimentos administrativos ou judiciários;

- a advocacia em saúde está dirigida às falhas institucionais que produzem ou agravam problemas individuais (dentro do nosso entendimento, deve-se pensar principalmente em danos à coletividade);

- a advocacia em saúde é inerentemente política, por assumir que há inadequação na distribuição de autoridade, recursos e acesso à informação;

- é mais efetiva quando dirigida a um tema específico; e

- é diferente da prestação direta de serviços.

Ressalte-se que a forma como a advocacia em saúde é exercida reflete uma filosofia, uma concepção de homem e sociedade, o que a vincula a uma preocupação ética constante.
Para o desenvolvimento do processo da advocacia em saúde torna-se necessário passar pelas seguintes etapas: clareamento do problema, coleta de dados sobre a situação, elaboração de estratégias para se atingir os objetivos, apresentação das estratégias para a clientela de tal forma que a mesma tenha autonomia para selecionar as que melhor lhe convierem, aplicação da estratégia escolhida e avaliação.

A primeira etapa, a do clareamento do problema, consiste no estudo do problema apresentado: qual o direito que está sendo violado. O problema deve ser específico e a legislação a respeito e os remédios institucionais existentes para o caso devem ser conhecidos. Saber se o problema tem apelo popular pode ser de ajuda no momento da sensibilização das autoridades.

A coleta de dados que digam respeito ao problema, localizando-o no tempo e no espaço, e sua apresentação de modo conciso para instrumentar o advogado na elaboração das estratégias, são fundamentais.

A elaboração de estratégias envolve o conhecimento da situação política atual, a seleção do interlocutor mais sensível, que possa dar uma solução ao problema, e a seleção da estratégia em si. Esta seleção depende da natureza do problema: se está na execução das ações, na elaboração de políticas públicas, de legislação específica, na modificação de leis e normas, ou na não-observância da legislação existente.

Algumas estratégias possíveis são citadas por Knitzer ${ }^{14} \mathrm{e}$ podem ser aplicadas à população em geral: o caso de advocacia, em que um caso individual motiva a ação; o "class litigation", que no Brasil tem seu equivalente na ação civil pública, em que um grupo de pessoas será beneficiada; a advocacia legislativa, que desenvolve esforços para assegurar que as normas existentes sirvam às necessidades $\mathrm{e}$ protejam os direitos das pessoas (iniciativa popular, audiência pública); e a advocacia administrativa, dirigida às agências governamentais.

A etapa de avaliação é de extrema importância: durante o processo, permite a reorientação do trabalho, e, ao final, a obtenção de informações sobre a correção ou não das estratégias escolhidas servirá de "insumo" para uma próxima causa.

Entretanto, até o momento não foram encontrados na literatura trabalhos referentes a esta etapa. Acredita-se que isso se deva ao fato da advocacia ser uma ação política e da dificuldade de se avaliar tal ação, uma vez que outras forças atuam a favor e contra, há jogo de interesses etc. Ou seja, nesta etapa, muitas das variáveis são incontroláveis. 


\section{A PRÁTICA DA ADVOCACIA EM SAÚDE}

Cuidado fundamental para a eficácia da advocacia em saúde é a definição dos seus limites. Isto por que, à primeira vista, qualquer movimento na direção da melhoria da saúde tem a aparência de uma "defesa" do direito a ela, o que pode dar a ilusão de se estar advogando por essa causa. Sob tal perpectiva, tudo que se faz em nome da saúde poderia ser considerado uma forma de advocacia, o que acabaria tornando seu conceito tão amplo quanto esvaziado e sua aplicação ineficaz.

A advocacia em saúde não se ocupa do direito à saúde propriamente dito, mas da sua realização em contextos localizados. Portanto, não se trata de um fim em si mesmo: o escopo da advocacia em saúde assume os contornos definidos por esta ou aquela finalidade, conforme a demanda que lhe é apresentada. Ou seja: nas situações em que o direito à saúde esteja totalmente implementado, a advocacia em saúde perde seu objeto.

Assim, por que seu objetivo não é único, genericamente formulado, mas fragmentado em objetivos pontuais, especificados circunstanciadamente, a advocacia em saúde não se identifica, em tese, com qualquer atuação considerada típica.

Equivale a dizer que a advocacia em saúde persegue propósitos pré-estabelecidos caso a caso, ainda que se aproveite de serviços técnicos alheios feitos sem comprometimento com tais propósitos. Um levantamento do grau de carência sanitária em determinada região, por exemplo, pode apresentar resultados potencialmente úteis à garantia do direito, mas apenas adquire status de advocacia quando é usado com essa finalidade. Não se faz advocacia em saúde por acaso, inconscientemente: a utilização política de uma atividade é que faz dela um instrumento estratégico.

No entanto, nem sempre esta abordagem é suficiente para evitar imprecisões, devido a ampla gama de atividades de que se serve a advocacia para a consecução de suas metas. O problema se instala quando, não raro, as metas intermediárias tomam a aparência de soluções finais: perde-se a noção de continuidade, pondo-se toda a estratégia a perder.

Para exemplificar, são comentadas algumas confusões em que se incorre usualmente.

Em primeiro lugar, é preciso distinguir a advocacia lato sensu, da advocacia stricto sensu, usualmente empregada para designar os serviços de um bacharel em direito. A despeito da terminologia, as posturas do advogado em sentido amplo e do advogado tradi- cional divergem radicalmente ao menos em um ponto: o envolvimento político na causa. Ainda que o bacharel tenha convicções políticas coincidentes com o direito que defende perante o Poder Judiciário, esta não é uma característica definidora do trabalho que desenvolve. Já no caso de um advogado em saúde, tal envolvimento é condição absolutamente necessária para a elaboração de estratégias políticas. Destacam-se, a seguir, alguns critérios de diferenciação entre serviços legais tradicionais e inovadores apresentados por Campilongo ${ }^{8 *}$, por se aplicarem mais que adequadamente:

a) "individual e coletivo":

“(...) A primeira grande distinção associa os serviços legais tradicionais ao atendimento individualizado e os serviços legais inovadores aos casos de interesse coletivo."

b) "apatia e organização":

Enquanto o modelo tradicional de serviços legais “(...) pressupõe uma relação hierarquizada entre advogados e clientes", os serviços legais inovadores os nivela: mesmo um bacharel se coloca como "(...) um dentre os participantes de uma luta ou postulação jurídica que beneficiará toda a comunidade. Confere a seu conhecimento profissional uma função social que suplanta a harmonização ou solução de litígios individuais."

c) "advogados e multiprofissionalismo":

“(...) Equipes compostas por advogados e profissionais de outras áreas demonstram que o direito não é o principal nem o menos relevante dos mecanismos de mudança social, mas apenas um dos muitos instrumentos de ação transformadora. Em verdade, a perspectiva multidisciplinar tende a resgatar ao direito e aos advogados funções até então encobertas ou desconhecidas pelos próprios juristas."

Não é difícil perceber quão restrita se torna a advocacia tradicional para a proteção do direito à saúde: este, declarado constitucionalmente como direito social, passa a ser tratado processualmente como um direito que assiste ao indivíduo e só por ele pode ser pleiteado.

As dificuldades de compatibilização entre o sistema normativo processual - de bases libeirais - e os recentes direitos sociais - que exigem do Estado determinadas prestações materiais - têm levado à insuficiência do Judiciário como forum das decisões garantidoras desses direitos. 
Nas palavras de Lopes ${ }^{16}$ :

“(...) a prestação do serviço depende da real existência dos meios: não existindo escolas, hospitais e servidores capazes e em número suficiente para prestar o serviço, o que fazer? Prestá-lo a quem tiver tido a oportunidade e a sorte de obter uma decisão judicial e abandonar a imensa maioria à fila de espera? Seria isto viável de fato e de direito, se o serviço público deve pautar-se pela sua universalidade, impessoalidade e pelo atendimento a quem dele mais precisar e cronologicamente anteceder os outros? Começam, pois, a surgir dificuldades enormes quando se trata de defender com instrumentos individuais um direito social."

Não se deve imaginar, no entanto, que a advocacia lato sensu possa prescindir da advocacia tradicional; se assim o fizesse, estaria perdendo a oportunidade de criar precedentes em casos exemplares. Aliás, um efeito paralelo é que quanto mais ações dessa natureza são ajuizadas, maior necessidade sentem os operadores do direito (juízes, promotores, delegados, advogados) de aprofundarem seu entendimento a respeito dos direitos sociais. Conseqüentemente, decisões mais esclarecidas vão aos poucos preenchendo de significado concreto a vaga noção de direito à saúde, o que só pode favorecer o ambiente em que atua o advogado em saúde, dentro ou fora dos tribunais.

“(...) o Judiciário, provocado adequadamente, pode ser um instrumento de formação de políticas públicas. Exemplo disto certamente é o caso da previdência social brasileira. Não fosse a atitude dos cidadãos de reivindicarem judicialmente e em massa seus interesses ou direitos, ficaríamos mais ou menos onde sempre estivemos. Mas aqui, também, o Judiciário há de dividir o papel de protagonista dos casos com os cidadãos e advogados iniciadores das ações. Resta ver, para que efetivamente se fale em políticas públicas, que haja iniciativas de caráter menos particularmente reivindicantes e mais sociais, como nas defesas de interesses difusos antes que de interresses individuais homogêneos, conforme se diz na moderna processualística.

Pela sua natureza, o debate judicial permite o avanço da democracia ao permitir as discussões de temas relevantes. Seja lá qual for a nossa opinião a respeito de temas como censura, liberdade de imprensa, aborto, direitos de minorias, direito de greve etc., sua submissão a uma discussão judicial amplia o espaço da democracia, porque exige, com mais ou menos sucesso, a racionalidade das propostas divergentes."
Quando se parte dessa dimensão ampliada de advocacia, outra confusão que comumente se estabelece é com o trabalho de educação em saúde.

Como já mencionado, a advocacia em saúde não formula reivindicações genéricas. Estas, apesar de se basearem no direito à saúde, estão invariavelmente voltadas para a solução de um problema específico. Sem a identificação correta do problema, não é possível vislumbrar nem a causa, nem o meio apropriado de garantir a saúde. Tomando-se uma área em que a causa de problemas de saúde em crianças foi associada à falta de amamentação, a distribuição gratuita de leite em pó será no mínimo inadequada. Nesta situação - não propriamente hipotética -, uma estratégia montada para criar condições objetivas de amamentação no local de trabalho da mulher, por exemplo, levaria a resultados mais eficazes.

O que precisa ficar bem claro é que não cabe ao advogado em saúde priorizar este ou aquele problema. É o potencial "cliente" quem conhece suas próprias necessidades e define sua demanda. A participação do advogado se dá num segundo momento, após a escolha pela solução de um problema e não de outro. Caso contrário, restaria desvirtuada a concepção de advocacia em saúde, que tem como um de seus pressupostos a participação do beneficiário, numa relação de igualdade para com o advogado.

Não é função, nem deve ser objetivo, de quem pretende advogar em saúde "inventar" uma causa. Esta postura ensejaria paternalismo, na melhor das hipóteses, e, na pior, oportunismos de interesses estranhos ao direito à saúde, sempre em nome dos menos privilegiados. Talvez a única reivindicação que um advogado em saúde possa eticamente promover em benefício de um cliente, sem um mínimo de informação sanitária, seja o acesso a serviços de educação em saúde.

As tarefas não se confundem: o educador prepara para a cidadania, o advogado promove o exercício da cidadania. Em outras palavras, a educação em saúde é condição absolutamente necessária para que a advocacia em saúde se manifeste. Essa relação de dependência que a advocacia em saúde guarda com a educação é que, curiosamente, torna possível ao cidadão se emancipar: à medida em que reconhece seus problemas e pleiteia solução para eles, vai se tornando seu próprio advogado.

Neste ponto é conveniente fazer uma advertência. Quem quer que se proponha a influenciar contextos decisórios, como é o caso do advogado em saúde, em algum momento busca aliança com grupos de pressão que fortaleçam seu poder de negociação. 
Tal comportarmento é freqüentemente interpretado como adesão pura e simples a princípios ou causas distantes dos objetivos originais ou, pior, como abandono de todo e qualquer princípio na perseguição de interesses menores.

Sem dúvida alguma, o fechamento em torno de questões comuns exige do advogado em saúde um comprometimento com outros grupos de interesses na forma de atuação conjunta. Isto não significa redução nos propósitos, senão o meio de alcançá-los. As palavras de $\operatorname{Lodi}^{15}$, que, embora voltadas ao público empresarial, contribuem para a exposição das diferenças que estão destacadas:

"(...) É curioso constatar que a expressão "LOBBY" tem uma conotação pejorativa."

“(...) Apesar de carregar consigo uma imagem de corrupção, do ponto de vista ético, o LOBBY não é necessariamente uma imoralidade, mas um instrumento neutro de influenciação do poder. A natureza ética de sua ação precisa ser vista à luz da situação, das intenções e dos meios que utiliza." “(...) não se deve confundir LOBBY e Relações Públicas. Estas últimas consistem em Comunicação com os diversos públicos que integram a sociedade, um dos quais é o Poder Público.O LOBBY restringe-se a uma ação junto ao poder público e representa um ato de influenciar sobre a decisão, enquanto Relações Públicas realiza apenas a comunicação em si."

“(...) A Oposição usa a expressão para acusar de corrupção os seus opositores, mas se esquece de que muitos grupos de interesse (como o movimento ecológico, o feminismo e outros) fazem LOBBY sem exercer necessariamente abuso de poder econômico. O LOBBY é sempre pejorativo quando outros são beneficiados; quando somos nós os beneficiados, não se usa a expressão."

Apenas com a ressalva de que não se pode considerar nenhum instrumento "neutro", por que determinante na consecução dos fins, entende-se a atividade do lobby como um meio indispensável de se fazer representar junto ao Estado. Sem isto, a advocacia em saúde perde espaço para outros interesses cuja satisfação pode inviabilizar as garantias que procura obter.

\section{OS AGENTES DA ADVOCACIA EM SAÚDE}

Partindo do conceito de advocacia em saúde, podemos considerar que qualquer indivíduo é um potencial advogado. $\mathrm{O}$ advogado pode ter uma forma- ção técnica ou ser leigo, pode agir individual ou coletivamente, pode, ainda, necessitar ou não de uma assistência técnica.

Dependendo de cada situação, tanto o perfil do advogado quanto a forma de advocacia em saúde vão sendo delineados de acordo com a intencionalidade do indivívuo. Isto se torna claro ao se tomar o papel de um técnico que durante o seu trabalho pode ter em mãos dados ou informações capazes de causar mudanças nas condições de saúde da população. $\mathrm{O}$ técnico assume o papel de advogado quando decide tomar uma atitude que passa da esfera técnica para a esfera política. Esta atitude pode ser desde o alerta à população até à participação no processo de mudança do sistema ou de uma situação particular.

As estratégias utilizadas pelas organizações-nãogovernamentais - ONGs - são exemplos pragmáticos do papel de advogado. Justamente porque as ONGs nascem quando algum direito é transgredido ou para firmar novos direitos, é da sua própria natureza desempenhar tal papel de modo permanente, uma vez que elas têm como finalidade melhorar as condições de vida intervindo em uma situação ou em uma política de saúde específica. As ONGs têm papel fundamental na reivindicação coletiva e no processo de negociação com os poderes públicos.

Quando um cidadão parte para a reivindicação do seu direito à saúde sai da condição de cidadão para a de cidadão-advogado. É sua característica ativa negociar, pressionar os poderes públicos para derrubar as barreiras que impedem o alcance de seu direito à saúde. Esta característica, no entanto, não é permanente como ocorre com as ONGs. Uma vez alcançados os objetivos propostos, o cidadão-advogado volta ao seu "estado de vigília".

Não resta dúvida de que para o alcance do direito à saúde a ação dos poderes públicos é fundamental. Por isso, são nas instituições do Estado que desembocam as ações do advogado.

O Executivo, Legislativo e o Judiciário possuem tarefas específicas, cabendo ao advogado em saúde, portanto, recorrer a estratégias distintas em cada âmbito. As especificidades, as lacunas, as normas que regem cada Poder deverão ser meticulosamente estudadas para a elaboração das estratégias de advocacia em saúde.

Como Estado Democrático de Direito, o Brasil tem na Constituição Federal os princípios e as normas que regem a democracia e a garantia dos direitos sociais, individuais, a liberdade, a segurança, o bem-estar, o desenvolvimento, a igualdade e a justiça. Portanto, a forma como o direito é declarado na lei afeta diretamente a atuação do advogado. 
O Poder Legislativo é a arena da elaboração e aprovação da lei. A lei, geralmente, é o produto das correlações de forças políticas e também pode nascer de uma demanda da sociedade civil.

Após a Constituição Federal de 1988, os mecanismos de elaboração de leis mudaram. As leis, além de terem origem nas mãos dos representantes eleitos, podem vir também das mãos do povo. $\mathrm{O}$ autor da demanda pode ser o autor da lei. A iniciativa popular garante este mecanismo (C.F., art.61, parágrafo $2^{\circ}$ ). Embora este mecanismo tenha sido pouco usado na experiência brasileira, o advogado deve estar atento para lançar mão deste recurso.

As leis elaboradas pelos representantes eleitos requerem a participação da sociedade civil, só que, desta vez, atuando como lobista. Assim, o advogado deve estar apto a negociar, a estudar o momento apropriado de se utilizar do lobby e como fazê-lo.

É ainda no campo legislativo que a sociedade civil tem direito de opinar a respeito de algum projeto de lei, por meio das audiências públicas (C.F., art. 58, parágrafo $2^{\circ}$, II) e também de referendar as leis aprovadas (C.F., art.14, II).

Como se pode ver, o Poder Legislativo é um campo fértil e pode ser muitas vezes o ponto de partida da transformação de uma demanda em direito, quando este ainda não vigora como lei.

Mas uma vez institucionalizado na forma de lei, o direito é a administração pública que tem a tarefa de garantir a eficácia desse direito e, o que é mais importante, de acordo com a lei. É preciso ter sempre em mente a absoluta vinculação da administração pública à previsão legal. Quando isso não ocorre, quando percebe-se a ineficácia da lei por omissão do Poder Executivo, o advogado deve lançar mão dos recursos, já utilizados anteriormente no campo legislativo, como o lobby, a negociação, para obter na prática o que está instituído em lei. É na administração pública que se encontram os canais institucionais onde o advogado em saúde pode, mais facilmente, influenciar nas decisões. No setor saúde tem-se, especificamente, os Conselhos de Saúde, que são órgãos colegiados que atuam na formulação de estratégias e no controle da execução das políticas de saúde (Lei Orgânica da Saúde, arts. $1^{\circ}$ e $\left.2^{\circ}\right)$.

A Constituição Federal conferiu a todo cidadão legitimidade para controlar os poderes públicos, incluindo a execução orçamentária da administração pública (art. 74, parágrafo $2^{\circ}$ ). Nesse sentido, é extremamente necessária a atuação do advogado em saúde nos casos em que o recurso financeiro é condição para a implementação de uma política de saúde. O Poder Judiciário abre um novo espaço de atuação para o advogado em saúde, principalmente quando for uma ONG.

Além de usar instrumentos disponíveis na Constituição Federal, como o mandado de injunção, o mandado de segurança e o habeas data, o advogado pode dispor da ação direta de inconstitucionalidade (art. 103) quando houver o descumprimento de algum preceito fundamental, podendo intervir tanto na administração pública como no Legislativo.

E, por último, cabe a atuação do advogado junto ao Ministério Público, órgão destinado à defesa dos interesses sociais e individuais indisponíveis. Cabe ao Ministério Público zelar pelo efetivo respeito dos serviços de relevância pública aos direitos assegurados na Constituição, promovendo as medidas necessárias à sua garantia (art. 129, II). Somente os serviços de saúde estão expressamente caracterizados como serviços de relevância pública (art. 197). Por conseguinte, o Ministério Público passa a ser o parceiro do advogado na promoção das medidas necessárias para garantir o direito à saúde.

\section{CONCLUSÃO}

Por vezes, concepções políticas não explícitas impedem a realização de atividades essenciais à população. A advocacia em saúde enfatiza o redimensionamento político dessas atividades, de modo a tornar possível a localização dos obstáculos, sem que com isso se possa atribuir a tal atividade um caráter menos profissional.

Acredita-se ter demonstrado que a advocacia em saúde só será competentemente praticada na medida em que sua função se mantenha nítida, suas condições estejam atendidas e seus instrumentos ajustados. A construção conceitual da advocacia em saúde não se esgota no que foi apresentado no presente trabalho, mas está permanentemente em aberto, uma vez que só se pode considerá-la completa quando associada à prática. Ela se pretende um embasamento teórico sobre o qual possa ser erguida a cidadania. 


\section{REFERÊNCIAS BIBLIOGRÁFICAS}

1. BARBER-MADDEN, R. La abogacia en salud publica. In: Dallari, S. G. et al. El derecho a la salud en la nueva Constitución brasileña. Washington, D. C., OPAS, 1992.

2. BARBOSA MOREIRA, J. C. A legitimação para a defesa dos interesses difusos no direito brasileiro. Rev. Forense (276): 1-6, 1981.

3. BIRD, B. J.; HAYWARD, D. J.; ALLEN, D. N. Conflicts in the commercialization of knowledge: perspectives from sciences and entrepreneurship. In: Entrepreneurship: theory and practice. Waco, Baylor University, 1993. p.57-77.

4. BOBBIO, N.; MATTEUCCI, N.; PASQUINO, G. Participação política. In: Dicionário de política. Brasília-DF, Universidade de Brasília, 1992. p. 888-90.

5. BOBBIO, N. Estado, governo, sociedade; por uma teoria geral da política. 4.ed. Rio de Janeiro, Paz e Terra, 1992.

6. BRASIL. Ministério da Saúde. Conferência Nacional de Saúde, 8. Brasília, 1986. Anais. Brasília, 1987.

7. CAMPILONGO, C. F. Representação política. São Paulo, Ática, 1988.

8. CAMPILONGO, C. F. Assistência jurídica e realidade social: apontamentos para uma tipologia dos serviços legais. In: Discutindo a assessoria popular. Rio de Janeiro AJUP/ FASE, 1991. (Coleção Seminários, 15).

9. COHN, A.; NUNES, E.; JACOBI, P.R.; KARSCH, U. S. A saúde como direito e como serviço. São Paulo, Cortez, 1991.

10. CONSTITUIÇÃO DA REPÚBLICA FEDERATIVA DO BRASIL. Brasília, Senado Federal, 1988.
11. DALLARI, D. A. Elementos de teoria geral do Estado. São Paulo, Saraiva, 1991.

12. GRINOVER, A. P. coord. A tutela dos interesses difusos. São Paulo, Max Limonad, 1984.

13. KHAN, A. J.; KAMERMAN, S. B.; MAC, G.; BRENDA, G. Child advocacy: report of a national baseline study. (DITEW Publication N.O. (OCD) 73-18). p. 7-95.

14. KNITZER, J. E. Child advocacy: a perspective. Am. J. Orthopsychiatry, 46: 200-16, 1976.

15. LODI, J. B. Lobby e holding: as bases do poder. São Paulo, Pioneira, 1986.

16. LOPES, J. R. de L. Judiciário, democracia, políticas públicas. In: Baptista, L.D. et al. Direito e Comércio Internacional: tendências e perspectivas: estudos em homenagem ao Professor Irineu Strenger. São Paulo, LTr, 1994. p. 560-78.

17. MANCUSO, R.C. Interesses difusos: conceito e legitimação para agir. São Paulo, Revista dos Tribunais, 1988.

18. SILVA, J.A. Curso de Direito Constitucional. São Paulo, Malheiros, 1992.

19. TEIXEIRA, S.M.F. Cidadania, direitos sociais e estado. Rev. Adm. Pública, 20: 115-40, 1986.

20. VILLONE, M. La collocazione istituzionale dell' interesse diffuso. In: La tutela degli interessi diffusi nel diritto comparato. Milano, Giufré, 1978. 